\title{
Editorial: Active Learning: Theoretical Perspectives, Empirical Studies, and Design Profiles
}

\author{
Robert Cassidy ${ }^{1 * t}$, Elizabeth S. Charles ${ }^{2+}$ and James D. Slotta ${ }^{3+}$ \\ ${ }^{1}$ Department of Education and Centre for Teaching and Learning, Concordia University, Montreal, QC, Canada, ${ }^{2}$ Dawson \\ College, Montreal, QC, Canada, ${ }^{3}$ Department of Curriculum, Teaching and Learning, Ontario Institute for Studies in \\ Education, University of Toronto, Toronto, ON, Canada
}

Keywords: research-practice partnership, pedagogical innovation, evidence-based teaching, active learning, design-based research, learning sciences

\section{Editorial on the Research Topic}

\section{Active Learning: Theoretical Perspectives, Empirical Studies, and Design Profiles}

\section{OPEN ACCESS}

Edited by:

Leman Figen Gul,

Istanbul Technical University, Turkey

Reviewed by:

Aydin Oztoprak,

TOBB University of Economics and

Technology, Turkey

*Correspondence:

Robert Cassidy

rob.cassidy@concordia.ca

tThese authors have contributed equally to this work and are listed in alphabetical order

Specialty section

This article was submitted to

Digital Education,

a section of the journal

Frontiers in ICT

Received: 21 December 2018

Accepted: 12 February 2019

Published: 07 March 2019

Citation:

Cassidy R, Charles ES and Slotta JD

(2019) Editorial: Active Learning:

Theoretical Perspectives, Empirical

Studies, and Design Profiles.

Front. ICT 6:3.

doi: 10.3389/fict.2019.00003
Scholars recognize our transition into a "Knowledge Society," where citizens are increasingly engaged in critical thinking, collaborative problem solving and evidence-based reasoning, and the workplace is defined by its complexity and rapid evolution (Hargreaves, 2003; Zuboff and Maxmin, 2004). As technologies like artificial intelligence and automation further affect the nature of work, educators, learning scientists and psychologists are now questioning whether our current educational approaches are adequately preparing students for this transforming landscape. In such a world, it is arguable that education should focus on helping students develop new skills, literacies and learning dispositions-e.g., complex problem-solving, digital literacy, initiative, self-direction and lifelong learning - in addition to basic skills and factual knowledge (Acosta and Slotta).

Educational researchers and practitioners have begun to respond to this challenge, leading to an instructional paradigm at the boundary of theory and practice, known as "active learning" (Bonwell and Eison, 1991). Translating research knowledge into practice, active learning develops and uses modes of instruction grounded in social constructivist theories and technological innovations to engage students and focus more intentionally on learning processes to improve learning outcomes. In the other direction, practitioners build highly effective active learning practices that challenge and inform our theoretical understanding, demonstrate effective principles of design, and are useful to other practitioners. In this productive exchange between research and practice, active learning designs are researched to produce rigorous evidence for what works and what does not for active learning methods.

New areas of research have been spawned by innovative learning technologies and the learning environments that support active learning, for instance, technology-rich classrooms such as SCALE-UP (Foote et al., 2014) and TEAL (Belcher, 2003). Among practitioners, there is a surge of interest in approaches such as the "flipped classroom" where students engage in the "lecture-like" activity at home, watching videos and reading texts, while they enact more active forms of problem solving, small group work, tutorial and recitation during class time (Bens, 2005; Lasry et al., 2014). Enjoying equal attention among instructors are student-centered methods such as peer instruction (Mazur, 1997; Balta et al., 2017; Cormier and Voisard; Fagen et al., 2002; Lasry et al., 2008, Schell and Butler), peer assessment (Panadero et al., 2018), peer annotations (Miller et al.), 2-stage exams (Wieman et al., 2014), to name a few. This movement has begun to generate new knowledge, as practitioners adapt and innovate theoretically driven, evidence-based pedagogies and technologies to make them work in real classroom settings.

Biesta (2015) has outlined two different roles for the way research can be useful to practice: (1) the technical, in which research provides practitioners with knowledge about effective teaching strategies, assessment practices, etc.; and (2) the cultural, in which research helps practitioners to 
acquire a different understanding of their practice. With respect to a technical role for research in practice, instructors typically find research knowledge inaccessible and irrelevantremoved from the contextual needs and realities of teachers (Hargreaves, 1997). In general, there is a knowledge translation chasm across which practitioners are expected to deconstruct abstract instructional principles and research findings and reconstruct them around their own learning context and content objectives. In a technical sense, educational research is failing practitioners.

Hence, there is an emerging consensus that effective and sustainable implementation of instructional innovations such as active learning can only be achieved through new ways of conceptualizing the transfer of knowledge from research to practice and vice versa (Biesta, 2007; Broekkamp and van HoutWolters, 2007; Vanderlinde and van Braak, 2010). ResearchPractice partnership (RPP) is one such conceptualization that offers the approach of co-design, where researchers and practitioners learn from each other (Coburn and Penuel, 2016; Fishman et al., 2013). RPP recognizes the importance of the practical expertise of practitioners and their role as frontline designers who consistently innovate and "make the magic happen." Practitioners must understand research findings and apply them in creating tools and methods that serve to implement principled pedagogies. These implementations then serve as a crucial source of insight for our wider community, rather than just implementations of the research. In focusing on "problems of practice," RPP interventions integrate practitioners' expertise and anchor the development of educational solutions in true collaborations.

It is increasingly clear that the transformation of the educational landscape should involve a thoughtful examination of the work of RPPs, which in turn can lead to new approaches to both research and practice. The traditional "knowledge push" approach (i.e., of research into practice) entails a unidirectional movement of generalized theory into practice, placing the researcher as the primary agent and holder of knowledge and the practitioner as the recipient. We seek to add a dynamic of "practice pull." We see practitioners as being useful to researchers, not as a mere testing ground, but as a source of insight from which researchers can reciprocally acquire a different understanding of their research and its objectives. Recognizing the limits of a "knowledge translation" approach to innovation, we seek to develop a social and cultural approach to innovation in which the voice of the practitioner is equal to that of the educational researcher. By capturing and sharing stories from RPPs and the wider active learning community, we seek to move beyond "pushing" and "pulling" into the more complex and recursive relationships of co-design, counderstanding and collaboration.

One example can be seen in our own work, to establish a professional learning community called SALTISE (Supporting Active Learning \& Technological Innovation in Studies of Education; see saltise.ca), which features a growing collection of successful implementations of active learning collected from practitioners, analyzed and codified by researchers. One goal of SALTISE is to help shed light on the tensions between the generalizability goals of research and the contextual realities of practitioners. Researchers look for relatively well-defined projects that result in publishable findings at the cusp of what is known or has been previously demonstrated, often relying on methodological traditions of comparative intervention studies. Practitioners are interested in longer-term refinement, experimentation and ongoing optimisation based on experience and feedback. Their primary goal is to improve student learning outcomes. SALTISE thus offers the promise of studying what Penuel (2014, p. 101), describes as interventions that are "developed in practice by participants in that practice, rather than in a controlled laboratory."

In this Frontiers in ICT Research Topic, 12 articles touch on these various aspects of mixing researcher and practitioner knowledge to understand and evaluate active learning in action. Three papers demonstrate the value of using a research-based theoretical perspective to examine effective active learning practices developed by practitioners. Schell and Butler analyse Peer Instruction through a cognitive psychology lens to derive principles that can help understand its effectiveness and provide guidance for practitioners who need to adapt it to fit their own implementation contexts. Brewe et al. similarly use a neurobiological lens to examine the efficacy of Modeling Instruction (MI) as a step toward understanding the changes in neural activity consequent to this style of learning. Furthermore, grounded in the theories of epistemological beliefs and conceptual change, Kalman and Lattery describe critical obstacles for learning post-secondary science and advance three instructional design principles for practically working through them.

Another seven papers empirically examine design principles in action. Ehrlick and Slotta present work in which the Knowledge Community and Inquiry model (Slotta and Najafi, 2013) is put sustainably and effectively into a situated practice through the adaptive iterations of design-based research (DBR). Similarly, Cormier and Voisard describe how the abstract "flipped" approach is concretely applied to an organic chemistry context and provide evidence for its effectiveness at driving student learning outcomes Acosta and Slotta present theoretical and practical design principles for the implementation of active learning curricula in grade 12 biology classrooms.

Researcher's theories have helped physics professors hone in on learning outcomes, as Marshman et al. engage the elusive "transfer of learning" problem through the design of a digital tutorial platform. The authors outline the impact and lessons learned from its implementation. Akiha et al. describe a crosssectional study of the instructional methods students experience as they advance through an educational system, identifying gaps in instructors' understanding of other parts of the system and emphasizing the need for inter-order communication and collaboration.

Miller et al. present the design and implementation of a computer-supported collaborative learning technology developed from practitioner experience, and present evidence for its increase in engagement and learning. Poellhuber et al. describe methods for the functional analysis of active learning spaces to identify the most valued features of these spaces and 
the relations among learning behaviors and attitudes toward the learning spaces.

Finally, two studies examine the types of changes in instructors that are associated with the adoption of active learning strategies. Fournier St-Laurent and Poellhuber present a case study of the changes that instructors undergo during the early stages of adopting active learning pedagogies; while, Laferrière presents the transformative nature of an ongoing DBR experiment on a sustained community of practice.

This collection of papers will hopefully engage a broad audience of researchers and practitioners as a knowledge community whose goal is to understand such pedagogical approaches. In what ways are they effective, and how do we know if they are effective? What aspects of student and teacher interactions are responsible for their efficacy?

\section{REFERENCES}

Balta, N., Michinov, N., Balyimez, S., and Ayaz, M. F. (2017). A meta-analysis of the effect of peer instruction on learning gain: Identification of informational and cultural moderators. Int. J. Educ. Res. 86, 66-77. doi: 10.1016/j.ijer.2017.08.009

Belcher, J. W. (2003). Improving student understanding with TEAL. The MIT Faculty Newsletters 16. Available online at: http://web.mit.edu/fnl/vol/162/ fnl162.pdf

Bens, I. (2005). Facilitating With Ease! Core Skills for Facilitators, Team Leaders and Members, Managers, Consultants, and Trainers, 2nd Edn. San Francisco, CA: Jossey Bass.

Biesta, G. (2007). Bridging the gap between educational research and educational practice: the need for critical distance. Educ. Res. Eval. 13, 295-301. doi: 10.1080/13803610701640227

Biesta, G. (2015). On the two cultures of educational research, and how we might move ahead: Reconsidering the ontology, axiology and praxeology of education. Eur. Educ. Res. J. 14, 11-22. doi: 10.1177/1474904114565162

Bonwell, C. C., and Eison, J. A. (1991). “Active learning: Creating excitement in the classroom," in ASHE-ERIC Higher Education Reports (Washington, DC: ERIC Clearinghouse on Higher Education).

Broekkamp, H., and van Hout-Wolters, B. (2007). The gap between educational research and practice: A literature review, symposium, and questionnaire. Educ. Res. Eval. 13, 203-220. doi: 10.1080/13803610701626127

Coburn, C. E., and Penuel, W. R. (2016). Research-practice partnerships in education: Outcomes, dynamics, and open questions. Educ. Res. 45, 48-54. doi: 10.3102/0013189X16631750

Fagen, A. P., Crouch, C. H., and Mazur, E. (2002). Peer instruction: results from a range of classrooms. Phys. Teach. 40, 206-209. doi: 10.1119/1.1474140

Fishman, B. J., Penuel, W. R., Allen, A.-R., Cheng, B. H., and Sabelli, N. (2013). Design-based implementation research: an emerging model for transforming the relationship of research and practice. Natl. Soc. Study Educ. 112, 136-156. https://www.sri.com/sites/default/files/publications/ fishman_penuel_allen_cheng_sabelli_2013.pdf

Foote, K. T., Neumeyer, X., Henderson, C., Dancy, M. H., and Beichner, R. J. (2014). Diffusion of research-based instructional strategies: the case of SCALEUP. Int. J. STEM Educ. 1, 1-18. doi: 10.1186/s40594-014-0010-8

Hargreaves, A. (2003). Teaching in the Knowledge Society: Education in the Age of Insecurity. New York, NY: Teachers College Press.
What are important principles underlying effective curricular designs? What are the most compelling applications of media and technology? How does active learning vary across different disciplines (e.g., physics, biology) and age levels (elementary, secondary and undergraduate education). We hope to engage both researchers and practitioners from a range of disciplines and contexts, to gather a wealth of evidence demonstrating the efficacy of new, principles and practical approaches that emphasize student inquiry, problem solving and collaboration.

\section{AUTHOR CONTRIBUTIONS}

All authors listed contributed equally to the work, and approved it for publication.

Hargreaves, D. H. (1997). In defence of research for evidence-based teaching: a rejoinder to Martyn Hammersley. Br. Educ. Res. J. 23, 405-419. doi: 10.1080/0141192970230402

Lasry, N., Dugdale, M., and Charles, E. (2014). Just in time to flip your classroom. Phys. Teach. 52, 34-37. doi: 10.1119/1.4849151

Lasry, N., Mazur, E., and Watkins, J. (2008). Peer instruction: from harvard to the two-year college. Am. J. Phys. 76, 1066-1069. doi: 10.1119/1.2978182

Mazur, E. (1997). Peer instruction. Upper Saddle River, NJ: Prentice Hall.

Panadero, E., Jonsson, A., and Alqassab, M. (2018). "Providing formative peer feedback: what do we know?" in The Cambridge Handbook of Instructional Feedback Cambridge Handbooks in Psychology, eds A. Lipnevich and J. Smith (Cambridge: Cambridge University Press). doi: 10.1017/9781316832134.020

Penuel, W. R. (2014). Emerging forms of formative intervention research in education. Mind. Culture Act. 21, 97-117. doi: 10.1080/10749039.2014.884137

Slotta, J. D., and Najafi, H. (2013). "Supporting collaborative knowledge construction with Web 2.0 technologies," in Emerging Technologies for the Classroom: A Learning Sciences Perspective, eds C. Mouza and N. Lavigne (New York, NY: Springer). 93-112. doi: 10.1007/978-1-4614-4696-5_7

Vanderlinde, R. and van Braak, J. (2010). The gap between educational research and practice: Views of teachers, school leaders, intermediaries and researchers. Br. Educ. Res. J. 36, 299-316. doi: 10.1080/01411920902919257

Wieman, C. E., Rieger, G. W., and Heiner, C. E. (2014). Physics exams that promote collaborative learning. Phys. Teach. 52, 51-53. doi: 10.1119/1. 4849159

Zuboff, S., and Maxmin, J. (2004). The Support Economy: Why Corporations Are Failing Individuals and the Next Episode of Capitalism. New York, NY: Penguin.

Conflict of Interest Statement: The authors declare that the research was conducted in the absence of any commercial or financial relationships that could be construed as a potential conflict of interest.

Copyright (c) 2019 Cassidy, Charles and Slotta. This is an open-access article distributed under the terms of the Creative Commons Attribution License (CC BY). The use, distribution or reproduction in other forums is permitted, provided the original author(s) and the copyright owner(s) are credited and that the original publication in this journal is cited, in accordance with accepted academic practice. No use, distribution or reproduction is permitted which does not comply with these terms. 